\title{
Uptake efficiency of surface modified gold nanoparticles does not correlate with functional changes and cytokine secretion in human dendritic cells in vitro
}

\author{
Kleanthis Fytianos, MSc ${ }^{\mathrm{a}, *}$, Laura Rodriguez-Lorenzo, $\mathrm{PhD}^{\mathrm{a}}$, Martin J.D. Clift, $\mathrm{PhD}^{\mathrm{a}}$, \\ Fabian Blank, $\mathrm{PhD}^{\mathrm{c}}$, Dimitri Vanhecke, $\mathrm{PhD}^{\mathrm{a}}$, Christophe von Garnier, $\mathrm{MD}^{\mathrm{c}}$, \\ Alke Petri-Fink, $\mathrm{PhD}^{\mathrm{a}, \mathrm{b}}$, Barbara Rothen-Rutishauser, $\mathrm{PhD}^{\mathrm{a}, \mathrm{c}}$ \\ ${ }^{\mathrm{a}}$ Adolphe Merkle Institute, University of Fribourg, Marly, Fribourg, Switzerland \\ ${ }^{\mathrm{b}}$ Department of Chemistry, University of Fribourg, Fribourg, Switzerland \\ ${ }^{\mathrm{c}}$ Respiratory Medicine, Bern University Hospital, Bern, Switzerland
}

\begin{abstract}
Engineering nanoparticles (NPs) for immune modulation require a thorough understanding of their interaction(s) with cells. Gold NPs (AuNPs) were coated with polyethylene glycol (PEG), polyvinyl alcohol (PVA) or a mixture of both with either positive or negative surface charge to investigate uptake and cell response in monocyte-derived dendritic cells (MDDCs). Inductively coupled plasma optical emission spectrometry and transmission electron microscopy were used to confirm the presence of Au inside MDDCs. Cell viability, (pro-)inflammatory responses, MDDC phenotype, activation markers, antigen uptake and processing were analyzed. Cell death was only observed for PVA-NH $\mathrm{NH}_{2}$ AuNPs at the highest concentration. MDDCs internalize AuNPs, however, surface modification influenced uptake. Though limited uptake was observed for PEG-COOH AuNPs, a significant tumor necrosis factor-alpha release was induced. In contrast, $(\mathrm{PEG}+\mathrm{PVA})-\mathrm{NH}_{2}$ and PVA-NH $\mathrm{N}_{2}$ AuNPs were internalized to a higher extent and caused interleukin-1beta secretion. None of the AuNPs caused changes in MDDC phenotype, activation or immunological properties.
\end{abstract}

Key words: Gold nanoparticles; Dendritic cells; Cellular uptake; Cell viability; Immunological properties

Abbreviations: APC, antigen presenting cells; AuNPs, gold nanoparticles; DLS, dynamic light scattering; ELISA, enzyme linked immunosorbent assay; FACS, fluorescence activated cell sorting; FCS, fetal calf serum; ICP-OES, inductively coupled plasma-optical emission spectroscopy; IL-1 $\beta$, interleukin 1 beta; LPS, lipopolysaccharide; MDDCs, monocyte derived dendritic cells; NPs, nanoparticles; PEG, poly ethylene glycol; PI, propidium iodide; PVA, poly vinyl alcohol; RPMI-1640, Roswell Park Memorial Institute; TEM, transmission electron microscope; TNF- $\alpha$, tumor necrosis factor alpha.

This study was supported by grants of the Swiss National Science Foundation NRP-64, Opportunities and Risks of Nanomaterials and the Adolphe Merkle Foundation.

Conflict of interest: The authors declare no conflicts of interest and are entirely responsible for the written manuscript and the data contained within it.

Disclosure statement: The authors would like to declare that there is no financial disclosure.

*Corresponding author at: Adolphe Merkle Institute, Université de Fribourg Route de l'ancienne Papeterie CP 209, CH-1723 Marly 1.

E-mail address: kleanthis.fytianos@unifr.ch (K. Fytianos).
A large body of research has previously been conducted upon the feasibility for engineered nanoparticles (NPs) to be used for biomedical applications. ${ }^{1-5}$ Due to their advantageous physicochemical properties, such as size and surface area, NPs have been proved capable of targeted therapy, site specific delivery, size-specific deposition and uptake. ${ }^{6}$ Current nanomedical applications employ targeted drug delivery to specific organs and designing strategies of nano-carrier based drugs by increasing the yield of the drug load while reducing side effects. $^{7}$ Gold NPs (AuNPs) have been considered as one of the most promising nanocarriers, due to their biocompatibility, ${ }^{8}$ and are intended for use in sensing, photothermal therapy, tracking and drug delivery. ${ }^{9}$ Commonly synthesized using the citrate reduction method, ${ }^{10}$ AuNPs are the most intensively studied inorganic NPs. ${ }^{11,12}$ 
The respiratory tract is in constant contact with inhaled antigens, ${ }^{13}$ and is one of the most suitable target organs for nanomedical applications. It possesses a vast surface area of approximately $140 \mathrm{~m}^{214}$ containing hundreds of millions of immune cells, such as macrophages and dendritic cells (DCs). ${ }^{15,16}$ DCs are antigen presenting cells which play an important role in immune regulation ${ }^{15}$ as the bridge between the innate and the adaptive immune system. ${ }^{15,17,18}$ Lung DCs capture inhaled antigens, and subsequently migrating to the draining lymph nodes presenting an antigen fragment to T-lymphocytes, initiating an immune response. ${ }^{19,20}$ For this reason, DCs in the human lung are promising targets for inhaled nanocarriers. ${ }^{21}$ Several studies in DCs have shown that AuNPs do not cause any significant cytotoxicity, cytokine production, activation and phenotype changes in vitro. ${ }^{22,23}$

Apart from the aforementioned beneficial effects of AuNPs, there remains limited understanding as to the AuNP-immune cell interaction, and their potential immunostimulation or immunosuppression effects. It has been stated that DCs can be specifically targeted by AuNPs with specific surface properties. ${ }^{4}$ By targeting DCs with nanocarriers, immune reactions can be tuned accordingly and drug delivery applications and targeted therapeutic approaches can become increasingly effective. ${ }^{3-5,24}$ Another important application is to design nanocarriers conjugated with active substances, i.e. antibody or antigen, as novel pulmonary vaccination systems. ${ }^{25}$

Although a broad range of different biomedical NP are already in (pre-clinical) use for diagnostic and therapeutic purposes, their effects on the immune system in relation to particle properties remain largely unknown to date. Therefore, we have used a library of AuNPs comprising an Au core (15 nm) coated with a layer of either PEG or PVA or a mixture of both with either a positive $(-\mathrm{NH} 2)$ or negative $(-\mathrm{COOH})$ surface charge. The influence of these surface modifications on uptake, induction of (pro)-inflammation, and immunological properties (i.e. maturation, antigen-uptake as well as processing) on monocyte-derived dendritic cells (MDDC) in vitro has been investigated. A pre-stimulation with lipopolysaccharide (LPS) was also performed to further study the effects of particles under inflammatory conditions.

\section{Methods}

AuNPs synthesis

Citrate-stabilized $\mathrm{Au}$ nanospheres (15 nm in diameter) were prepared as described. ${ }^{10,26,27}$ Briefly, a $0.5 \mathrm{mM}$ aqueous tetrachloroauric acid $\left(\mathrm{HAuCl}_{4} \times 3 \mathrm{H}_{2} \mathrm{O}\right.$; Sigma-Aldrich, St. Louis, MO, USA) solution was boiled for $20 \mathrm{~min}$ in the presence of $1.5 \mathrm{mM}$ sodium citrate $\left(\mathrm{C}_{6} \mathrm{H}_{5} \mathrm{O}_{7} \mathrm{Na}_{3}\right.$; SigmaAldrich, St. Louis, MO, USA). Within $20 \mathrm{~min}$ the color of the solution changed to red indicating the formation of AuNPs.

In order to produce the polymer-capped particles, aqueous solutions containing an adequate amount of polymer were prepared. PEG (Creative PEGWorks, Winston Salem, NC, USA; $\mathrm{Mw}=5,000 \mathrm{~g} / \mathrm{mol}$ ) and PVA (Clariant, Muttenz, Switzerland; $\mathrm{Mw}=14,000 \mathrm{~g} / \mathrm{mol}$ ) were chosen as they have been regarded safe for use ${ }^{28,29}$ due to their improvement upon NP stability and biocompatibility. ${ }^{30}$ The amount of PEG was calculated to provide the AuNPs with about 15 PEG molecules per $\mathrm{nm}^{2}$ surface, independent of the molar mass of the PEG. The PEG was dissolved in water by ultrasonication of the solution for 15 min. Subsequently, PEG solution and the NPs suspension were mixed under stirring (200 rpm). To guarantee that coating was complete, the reaction mixture was stirred overnight at room temperature (RT). For the PVA samples, the PVA solution contained a mixture of polyvinyl alcohol (Mowiol 3-83, Omya AG, Switzerland) and either vinyl alcohol/vinylamine copolymer (M12, Erkol S.A, Spain) or carboxylic-modified PVA (KL506, Kuraray Specialties Europe GmbH, Germany) at a ratio of 45 . The PVA solutions were prepared by dissolving the powder in water, followed by rapidly heating the solution to $90{ }^{\circ} \mathrm{C}$ for $15 \mathrm{~min}$ and cooling to RT. The respective polymer solution, which was previously treated by ultrasound for $15 \mathrm{~min}$, was then added drop-wise under shaking conditions to $100 \mathrm{~mL}$ of synthesized AuNPs. The mixture was allowed to react at RT for $24 \mathrm{~h}$. Polymer-coated AuNPs were then centrifuged $(10,000 \mathrm{~g}, 1 \mathrm{~h})$ twice to remove any excess polymer and then re-dispersed in $10 \mathrm{~mL}$ of PBS.

The quantification of endotoxin content of all AuNP (SI and Table S1) solutions was performed using the PYROGENTTM-5000 Limulus Amebocyte Lysate assay (Lonza, USA) and the Pierce LAL Chromogenic Endotoxin Quantification kit (cat. no.: 88282; Thermo Scientific, Waltham, MA, USA). Briefly, in accordance with the kit guidelines, $20 \mu \mathrm{g} / \mathrm{mL}$ AuNPs of all conditions were tested. $100 \mathrm{ng} / \mathrm{mL}$ LPS was used as positive control.

\section{AuNPs characterization}

Particle diameter analysis of citrate-coated Au-NPs was estimated by transmission emission microcopy (TEM). TEM images were taken using a Philips CM-100 Microscope operating at $80 \mathrm{kV}$. The sample was diluted 2-fold in water and $10 \mu \mathrm{L}$ was then pipetted onto a 400 mesh $\mathrm{Cu}$ film grid (Plano GmbH, Wetzlar, Germany) and dried at RT prior image capture.

The hydrodynamic diameter of AuNPs was estimated by dynamic light scattering (DLS). Measurements were carried out at RT and at a scattering angle of $80^{\circ}$ using a 3D LS spectrometer (LS instruments) equipped with a $21 \mathrm{~mW} \mathrm{HeNe} \mathrm{laser} \mathrm{(excitation}$ wavelength: $632.8 \mathrm{~nm}$ ). Experiment duration was $\leq 4 \mathrm{~min}$ and repeated three independent times. The corresponding correlation functions were analyzed using the constrained, regularized 'Cumulant method'. UV-Vis spectra of the polymer-coated AuNPs were recorded using a Jasco V-670 spectrophotometer. The samples were diluted 10-fold in PBS or cell culture medium. The colloidal stability was tested by incubating the AuNPs in Roswell Park Memorial Institute (RPMI) 1640 medium with $10 \%$ fetal calf serum (FCS), 1\% L-glutamine, 1\% penicillinstreptomycin, $10 \mathrm{ng} / \mathrm{mL}$ granulocyte macrophage-colony stimulating factor (GM-CSF) and $10 \mathrm{ng} / \mathrm{mL}$ interleukin (IL)-4 at $37{ }^{\circ} \mathrm{C}$ and $5 \% \mathrm{CO}_{2}$ for $2 \mathrm{~h}$ and $24 \mathrm{~h}$. The surface charge of polymer-coated AuNPs was measured in $50 \mu \mathrm{g} / \mathrm{mL}$ in $10 \mathrm{mM}$ PBS ( $\mathrm{pH} \mathrm{7)}$ and water ( $\mathrm{pH} 6$ ) at $25^{\circ} \mathrm{C}$ using phase amplitude light scattering (PALS) zeta potential analyzer (Brookhaven 
ZetaPALS). The Smoluchwski model was fitted to 5 cycles of electrophoretic mobility (EPM) measurements and 10 replicates were obtained for each sample to estimate the mean and the standard deviation (SD).

\section{Human MDDC cultures and AuNPs exposure}

Monocytes were isolated from human whole blood as previously described, ${ }^{1}$ seeded either into 6-well plates ( $3 \mathrm{~mL} /$ well, $10^{6}$ cells $\left./ \mathrm{mL}\right)$ or 12 -well plates $(1 \mathrm{~mL} /$ well, $10^{6}$ cells $/ \mathrm{mL}$ ) and cultured in RPMI 1640 supplemented medium (10\% FCS, 1\% L-Glu, 1\% Pen-Strep, $10 \mathrm{ng} / \mathrm{mL}$ GM-CSF and $10 \mathrm{ng} / \mathrm{mL}$ IL-4) for 6 days at $37{ }^{\circ} \mathrm{C}, 5 \% \mathrm{CO}_{2}$ allowing differentiation into MDDC. To induce maturation, MDDCs were co-stimulated with $100 \mathrm{ng} / \mathrm{mL}$ of lipopolysaccharide (LPS) derived from Escherichia coli (L65-29-1MG, Sigma Aldrich) (to induce maturation) and AuNPs at either $20 \mu \mathrm{g}$ or $100 \mu \mathrm{g} / \mathrm{mL}$ for $16 \mathrm{~h}$. As a control, MDDCs were also exposed to AuNPs at each dose noted without the addition of LPS. Briefly, cell supernatant was removed and the adherent MDDCs were treated with $3 \mathrm{~mL}$ of medium which contained the AuNPs in suspensions.

Inductively coupled plasma-optical emission spectroscopy (ICP-OES)

After $16 \mathrm{~h}$ of particle exposure in suspension, cells were collected in $15 \mathrm{~mL}$ Falcon tubes. Samples were centrifuged two times at $4{ }^{\circ} \mathrm{C}(500 \mathrm{~g} / 8 \mathrm{~min})$ and washed with $1 \times \mathrm{PBS}$ and kept at $4{ }^{\circ} \mathrm{C}$ until analysis could occur. At $24 \mathrm{~h}$ before measurement, the cells were digested in $1 \mathrm{~mL}$ Aqua Regia to dissolve the AuNPs. After digestion, samples were filtered $(0.22 \mu \mathrm{m}$ pore diameter, Millipore) and diluted in $10 \mathrm{~mL}$ with MilliQ water (1:10 dilution) and measured using ICP-OES (Optima 7000DV, Perkin Elmer). Measurements were performed at a wavelength of $242.8 \mathrm{~nm}$, at an axial plasma view. The plasma flow was $15 \mathrm{~L} / \mathrm{min}$ and the sample flow rate $1.5 \mathrm{~mL} / \mathrm{min}$. A washing step was performed by the instrument between each measurement and each sample was measured three times on each repetition. The $\mathrm{Au}$ mass was calculated as pg/cell by dividing the obtained $\mathrm{Au}$ mass per cell number/well.

\section{Transmission electron microscopy (TEM)}

After AuNP exposure, MDDCs were fixed with 2.5\% glutaraldehyde in HEPES buffer (Sigma Aldrich, St. Luis, MO, USA) and dehydrated, embedded and sectioned as described in Blank et al. ${ }^{1}$ TEM pictures were captured using a Hitachi H-1700 TEM (Hitachi, Japan) at a resolution of $4.78 \mathrm{~nm} /$ pixel (overviews) and $1.96 \mathrm{~nm} / \mathrm{pixel}$ (details) and recorded on a SIS Morada CCD camera (Olympus, Japan).

\section{Phase contrast pictures}

Phase contrast pictures at a magnification $\times 40$ were captured (Motic, AE2000 Inverted Microscope Motic Deutschland $\mathrm{GmbH}$, Wetzlar, Germany) in order to characterize the morphology of the cells following AuNP exposure.

\section{Pro-inflammatory effects}

After AuNPs exposure for $16 \mathrm{~h}$, the concentrations of tumor necrosis factor-alpha (TNF- $\alpha$ ) and interleukin-1beta (IL-1 $\beta$ ) released from the cells into the supernatants were measured by enzyme linked immuno-sorbent assay (ELISA). The assay was performed according to the manufacturer's instructions (Human TNF-alpha Quantikine ELISA Kit, Product Number: DTA00C, R\&D Systems for TNF- $\alpha$ and SLB50 R\&D Systems for IL-1 $\beta$ ). For both experiments cells treated with $100 \mathrm{ng} / \mathrm{mL}$ LPS for $16 \mathrm{~h}$ were used as a positive control.

\section{Flow cytometry}

\section{Annexin V and Propidium Iodid assay}

The Annexin-V-Fluos assay (cat. no. 11828681001, Roche Diagnostics, Zug Switzerland) was utilized to measure apoptotic (annexin V) and death (propidium iodide (PI)) cell populations. Briefly, $10^{6}$ exposed cells were incubated with annexin V-PI mix for $15 \mathrm{~min}$ at RT and analyzed by flow cytometry. Cells were treated with $2 \mathrm{mM}$ camptothecin (cat. no. C9911, Sigma Aldrich, Saint Luis, MI, USA) for $16 \mathrm{~h}$ as a apoptotic positive control and cells incubated at $-80{ }^{\circ} \mathrm{C}$ for 30 min were used as a positive control for cell death.

\section{Phenotype and maturation markers, antigen uptake and antigen processing}

After AuNP exposure the cells were washed, centrifuged $\left(0.5 \mathrm{rcf} / 8 \mathrm{~min} / 4{ }^{\circ} \mathrm{C}\right)$ and resuspended in $1 \mathrm{~mL}$ FACS buffer (PBS $+1 \%$ BSA $+0.1 \%$ NaN3). Prior to antibody labeling cells were incubated with Fc-block receptor (Miltenyi Biotech - cat. no.: 130-059 901) for $10 \mathrm{~min}$ to inhibit Fc-receptor binding of specific antibodies. Cells were labeled with anti-human CD1c-Pacific Blue (Biolegend, cat. no.: $331507)$. CD83-Biotinylated-Streptavidin-PE-Cy 5 (eBioscience, cat. no.: 13-0839-80 and 15-4317-82) and MHC-II-PE-Cy7 (eBioscience, cat. no.: 25-9952-41). Relevant isotype control antibodies from Mouse IgG were used. Labeling was performed on ice. OVA-Alexa Fluor 647 (Molecular Probes, cat. no.: 034784) was utilized to measure antigen uptake capacity and DQ-OVA (Molecular Probes, cat. no.: D12053) to determine antigen processing. MDDCs were incubated for $0,30,60$ and $120 \mathrm{~min}$ at $37^{\circ} \mathrm{C}$ or on ice (negative control) to measure antigen uptake and processing. Figure S4 illustrates the gating strategy t. Flow cytometry experiments were performed in the BD-LSR Fortessa and data were analyzed using FlowJo software (Tree Star).

\section{Statistics}

Results are presented as mean $(n=3$; i.e. independent experiments) \pm standard deviation (SD). The Mann-Whitney U-test comparison for non-parametric data was utilized. The comparisons were performed by using Microsoft Excel. In order to calculate a potential relationship, the number of AuNPs (ICP-OES values) versus the concentration of secreted cytokines was plotted against one another. 


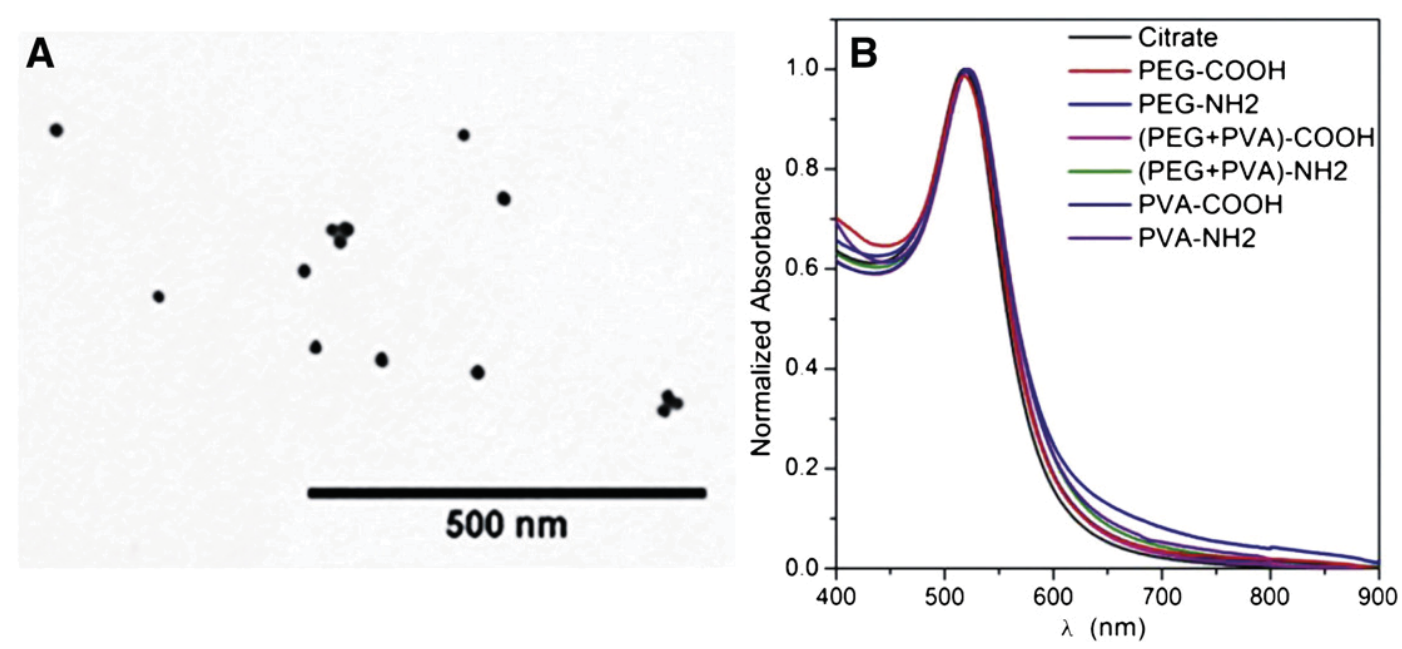

Figure 1. (A) Representative TEM image of citrate-coated AuNPs. (B) Extinction spectra of the polymer coated AuNPs after dilution in PBS. The spectra were normalized based on their maximum wavelength.

Table 1

Size and surface charge of polymer coated Au-NPs.

\begin{tabular}{|c|c|c|c|c|}
\hline \multirow[t]{2}{*}{ Au-NPs } & \multirow[t]{2}{*}{$\mathrm{D}_{\mathrm{h}}(\mathrm{nm})^{\mathrm{a}}$} & \multirow{2}{*}{$\begin{array}{l}\text { Polydispersity } \\
(\%)\end{array}$} & \multicolumn{2}{|l|}{$\zeta(\mathrm{mV})$} \\
\hline & & & 10 mM PBS (pH 7) & $\mathrm{H}_{2} \mathrm{O}(\mathrm{pH} 6)$ \\
\hline Citrate & $13.5 \pm 3.3$ & 3.3 & Aggregated & $-24.0 \pm 1.5$ \\
\hline PEG-COOH & $37.4 \pm 2.3$ & 16.8 & $-19.9 \pm 6.5$ & $-17.2 \pm 2.4$ \\
\hline PEG-NH ${ }_{2}$ & $19.7 \pm 0.2$ & 9.0 & $-21.9 \pm 8.2$ & $16.1 \pm 1.8$ \\
\hline$(\mathrm{PEG}+\mathrm{PVA})-\mathrm{COOH}$ & $22.1 \pm 0.2$ & 6.6 & $-32.3 \pm 6.2$ & $-35.1 \pm 1.1$ \\
\hline$(\mathrm{PEG}+\mathrm{PVA})-\mathrm{NH}_{2}$ & $55.1 \pm 0.6$ & 21.0 & $-24.1 \pm 4.9$ & $12.9 \pm 1.3$ \\
\hline PVA-COOH & $22.5 \pm 0.6$ & 9.5 & $-28.9 \pm 3.5$ & $-38.7 \pm 0.7$ \\
\hline PVA-NH ${ }_{2}$ & $80.4 \pm 0.5$ & 35.0 & $7.6 \pm 2.8$ & $20.4 \pm 2.1$ \\
\hline
\end{tabular}

Zeta potential was measured in 10 replicates (mean $\pm \mathrm{SD}$ ).

${ }^{a}$ Mean hydrodynamic diameter obtained by dynamic light scattering (DLS) at room temperature and at scattering angle of $80^{\circ}, 90^{\circ}$, and $100^{\circ}$. DLS measurements were carried out in triplicate (mean $\pm \mathrm{SD}$ ).

\section{Results}

\section{AuNPs characterization}

Figure 1, $A$ shows a representative TEM image of the citrate-coated AuNPs with the average diameter $15 \pm 2 \mathrm{~nm}$. The localized surface plasmon resonance (LSPR) of citrate-coated AuNPs was centered at $518 \mathrm{~nm}$, with a red-shift to $520-522 \mathrm{~nm}$ following polymer coating upon their surface (Figure 1,B) which is attributed to the increased refractive index due to the presence of the polymer. ${ }^{31}$ The stability of the polymer-coated AuNPs in complete culture medium was confirmed by the lack of an LSPR shift to longer wavelengths ${ }^{32}$ over a $24 \mathrm{~h}$ period (Figure S1).

Hydrodynamic diameters of polymer-coated AuNPs, as determined by DLS, showed all functionalized AuNPs to have an average size greater than the citrate coated AuNPs, thus demonstrating the presence of the polymer (Table 1). The size of the particles was in the range of about $20 \mathrm{~nm}$ for the PEG-NH $(\mathrm{PEG}+\mathrm{PVA})-\mathrm{COOH}$ and PVA-COOH, $37 \mathrm{~nm}$ for PEG$\mathrm{COOH}, 55 \mathrm{~nm}$ for (PEG + PVA)- $\mathrm{NH}_{2}$ and $80 \mathrm{~nm}$ for PVA-NH ${ }_{2}$. Zeta potential measurements (Table 1) revealed that the AuNPs re-dispersed in water displayed the expected positive charge for the amine-functional layers and a negative charge for the carboxylic-functional layers. However, when functionalized AuNPs were re-dispersed in PBS, PEG-NH2 and (PEG + PVA)-NH2 coated AuNPs presented negative zeta potentials, despite containing positively charged amine groups $\left(-\mathrm{NH}^{3+}\right)$. This may be attributed to the reduced number of protonated amino groups (1.5-2 fold) at $\mathrm{pH} 7$ and the strong negative zeta potential of citrate anions present. ${ }^{33}$

\section{Cellular uptake of AuNPs}

Internalization of AuNPs by MDDCs was investigated at two concentrations, i.e. 20 and $100 \mu \mathrm{g} / \mathrm{mL}$. The quantification of particle association and/or internalization was evaluated by ICP-OES. Cellular uptake of AuNPs was related to their composition (Figure 2). Notably, only PEG-COOH $(5.1 \pm 2.8$ to $51.4 \pm 21.0 \mathrm{pg} / \mathrm{cell}), \mathrm{PVA}-\mathrm{NH}_{2}(348.7 \pm 29.4$ to $517.6 \pm$ $24.6 \mathrm{pg} / \mathrm{cell})$ and (PEG + PVA)-COOH (89.6 \pm 48.6 to $225.4 \pm 3.3 \mathrm{pg} / \mathrm{cell}$ ) AuNPs displayed a significant dosedependent increase in particle uptake. Furthermore, the highest cellular uptake occurred with PVA- $\mathrm{NH}_{2}$ particles. Non-exposed cells were employed as a negative control in which no signals were detected (data not shown). 

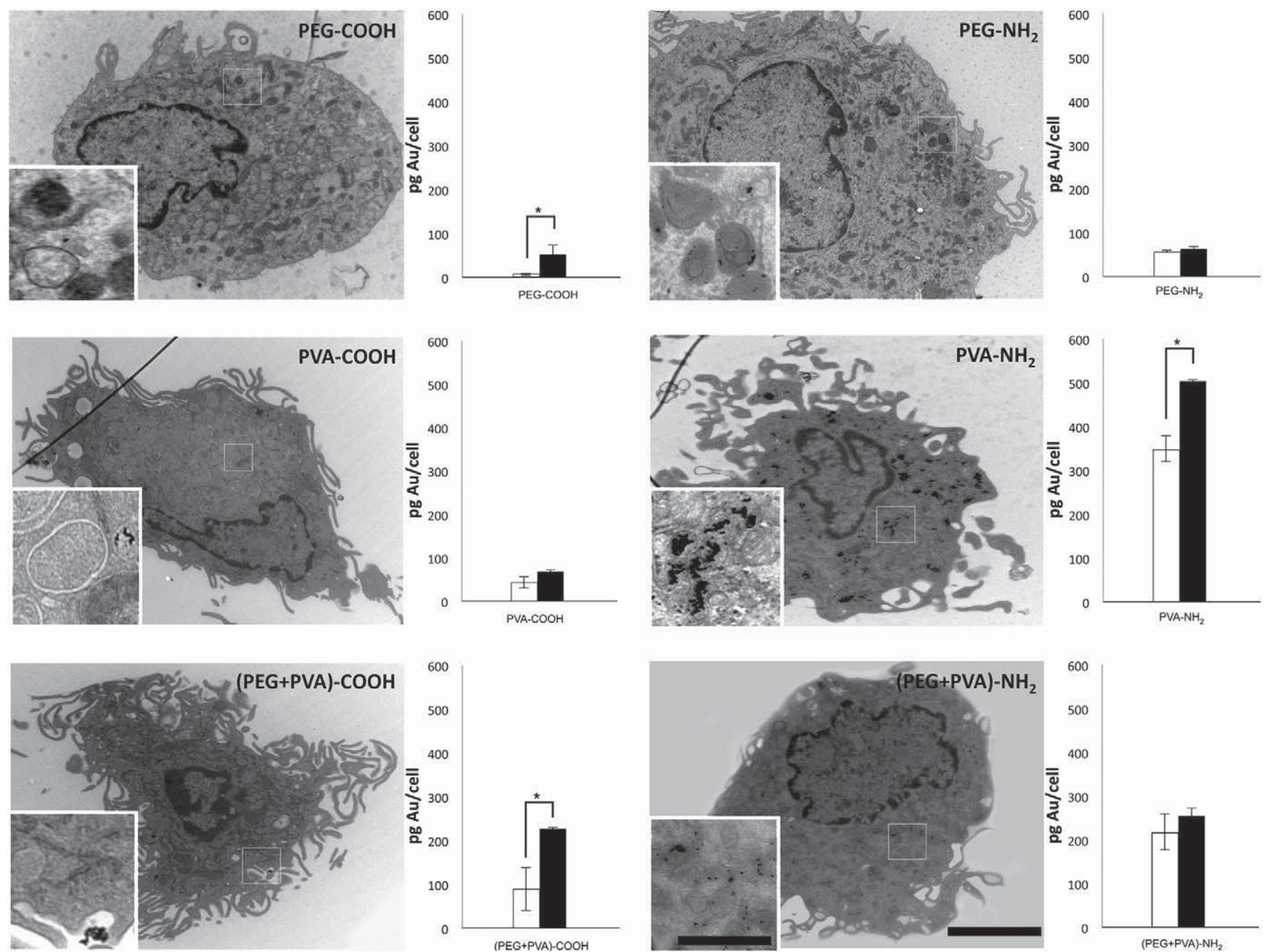

Figure 2. Cellular uptake of AuNPs by MDDCs shown with TEM images and ICP-OES measurements. A few particles are present on the PEG-COOH sample as illustrated in the TEM image and by the ICP-OES measurements. In the case of PEG-NH $\mathrm{N}_{2}$ and PVA-COOH, (PEG + PVA)-COOH the amount of NPs is increased compared to the PEG-COOH AuNPs treated cells, while the highest numbers are observed intracellularly when MDDCs were exposed to PVA-NH ${ }_{2}$ AuNPs and (PEG + PVA)- $\mathrm{NH}_{2}$ AuNPs. The highest uptake is observed when AuNPs are functionalized with PVA-NH $\mathrm{N}_{2}$ and (PEG $\left.+\mathrm{PVA}\right)-\mathrm{NH} \mathrm{H}_{2} \mathrm{AuNPs}$. Error bars represent the mean $\pm \mathrm{SD}$ and $*$ a significant difference of $P<0.05$. The results are expressed as $\mathrm{pg} \mathrm{Au} / \mathrm{cell}(\mathrm{n}=3)$.

Additional investigation via TEM also showed all AuNPs, to be associated with, and furthermore, present inside MDDCs after $20 \mu \mathrm{g} / \mathrm{mL}$ exposure for $16 \mathrm{~h}$ (Figure 2). All AuNPs were found within vesicular structures, whereas the PEG-COOH AuNPs were in addition observed free within the cytoplasm. Nonexposed cells were employed as a negative control in which no electron-dense structures resembling AuNPs were seen.

\section{Cell viability}

Phase-contrast microscopy analysis (Figure 3, $A$ ) and results of the Trypan blue exclusion assay (Figure S2) indicate that viability of AuNP treated cells was similar to that of untreated MDDCs control. Viability was significantly decreased following exposure to $100 \mu \mathrm{g} / \mathrm{mL}$ of PVA-NH2 AuNPs, both in the presence and absence of LPS (Figure S2). Apoptosis and cell death (necrosis) were assessed by flow cytometry employing annexin V and PI staining, respectively. There was no increase in apoptotic cells for all conditions, i.e. AuNPs with and without
LPS (Figure 3, B), and only cells treated with the $100 \mu \mathrm{g} / \mathrm{mL}$ of PVA-NH $\mathrm{N}_{2}$ AuNPs showed a significant increase of necrotic cells (Figure 3, C).

\section{Cytokine secretion}

No significant increase in TNF- $\alpha$ (Figure $4, A$ ) or IL-1 $\beta$ (Figure 4, $B$ ) was observed, only MDDCs treated with PEG-COOH AuNPs elicited a significant rise in TNF- $\alpha$ levels at these three particle concentrations. Due to the effect of PVA-NH $\mathrm{N}_{2}$ AuNPs in cell viability, the low levels of TNF- $\alpha$ produced derive from a fewer number of viable cells (Figure 4, A). PVA- $\mathrm{NH}_{2}$ and (PEG + PVA)- $\mathrm{NH}_{2}$ AuNPs induced significant IL-1 $\beta$ release at $100 \mu \mathrm{g} / \mathrm{mL}$ in the presence of LPS. In the presence of LPS, no significant increase upon particle exposure was observed in comparison to the LPS treatment alone.

In the presence of LPS, the secretion of both cytokines was increased significantly, yet no significant synergistic effects in the presence of the AuNPs were observed compared against 
A
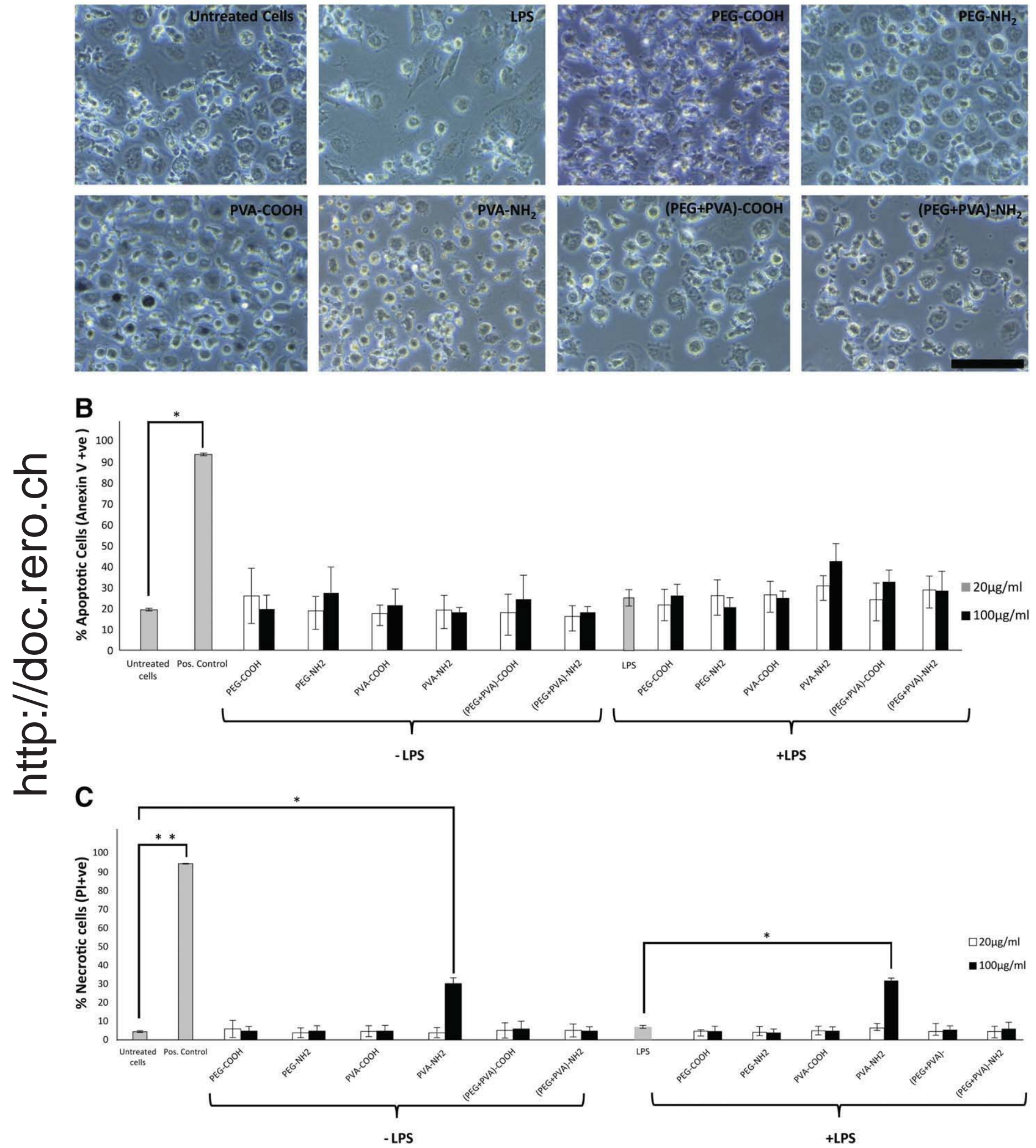

Figure 3. Assessment of cell viability. (A) The surface functionalization of AuNPs is not influencing cell viability and morphology, only when cells were exposed to $100 \mu \mathrm{g} / \mathrm{mL}$ of PVA- $\mathrm{NH}_{2}$ AuNPs fewer viable cells could be observed as shown by phase contrast microscopy. LPS has no effect on viability. Scale bar: $100 \mu \mathrm{m}$. (B) Levels of apoptotic (annexin V) and dead cells (PI) were assessed by flow cytometry. No apoptosis was induced under any conditions, whereas the highest concentration of PVA- $\mathrm{NH}_{2}$ AuNPs induced a significant decrease of viable cells. Camptothecin was used as an apoptotic positive control and cells incubated at $-80{ }^{\circ} \mathrm{C}$ for 30 min were used as a positive control for cell death. (error bars: mean $\pm \mathrm{SD},{ }^{* *} P<0.01, \mathrm{n}=3$ ). 

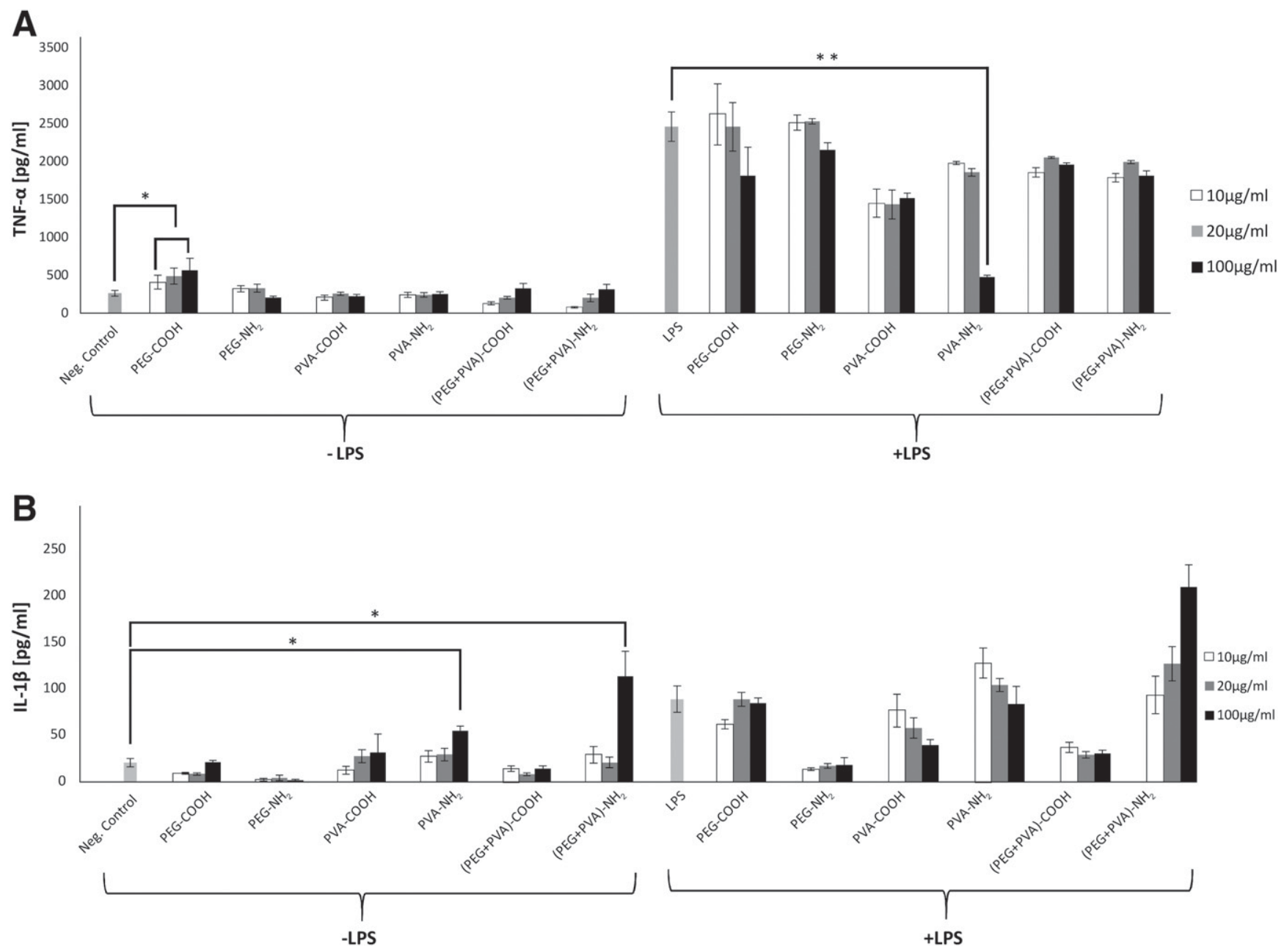

Figure 4. Cytokine secretion of MDDCs exposed to AuNPs in the presence or absence of LPS. (A) Only PEG-COOH AuNPs show a significant increase of TNF- $\alpha$ production. Untreated cells were used as negative control and cells exposed to $100 \mathrm{ng} / \mathrm{mL}$ LPS as positive control. (B) No significant amounts of IL-1 $\beta$ were produced for most of the particles at 10 and $20 \mu \mathrm{g} / \mathrm{mL}$. Note the concentration dependent effect for PVA-NH $\mathrm{N}_{2}$ and $(\mathrm{PEG}+\mathrm{PVA})-\mathrm{NH} \mathrm{H}_{2}$ AuNPs, as well as the effect of LPS. Untreated cells were used as negative control and cells exposed to $100 \mathrm{ng} / \mathrm{mL}$ LPS as positive control (error bars: mean $\pm \mathrm{SD}, * P<0.05$, $* * P<0.01, \mathrm{n}=3-6)$.

non-LPS treated MDDCs. Calculation of the associated AuNPs/ cell in relation to the amount of secreted cytokines showed no correlation (Figure S8).

For both cytokines, we included controls with the polymers only that showed no increase in TNF- $\alpha$ and IL- $1 \beta$ secretion (Figure S7).

Phenotype and maturation characterization of MDDC upon particle exposure

Flow cytometry was utilized to assess the phenotype (CD1c) and maturation status (MHC-II and CD83) of MDDCs following AuNPs exposure. Only $20 \mu \mathrm{g} / \mathrm{mL}$ AuNPs were investigated since no cytotoxicity or (pro)-inflammatory effects were observed at this concentration. None of the AuNPs significantly altered the expression of CD1c, MHC-II or CD83 on MDDCs (Figure 5, A).

\section{Antigen uptake and processing in the presence of AuNPs}

Neither antigen uptake (Figure 5, B), nor antigen processing capacities (Figure 5, C) of the MDDCs were significantly altered in the presence of any of the AuNPs tested. Furthermore, the expression of MHC-II and CD83 markers in the presence of OVA was also measured to assess the surface marker expression of exposed cells in the presence of a known antigen (Figures S5 and S6). Results indicated that marker expression was not altered following AuNP exposure.

\section{Discussion}

In order to assess the great potential of nano-sized particles for novel diagnostic and therapeutic applications, standardized synthesis and thorough characterization methods are required In addition, well characterized and realistic biological systems are needed for accurate in vitro assessment of the impact of NPs, ${ }^{1}$ such as MDDCs which represent a realistic in vitro alternative to study possible immune responses. A potential alteration of an immune response could determine the fate of a novel therapeutic and/or diagnostic approach. ${ }^{1,4,5}$ 

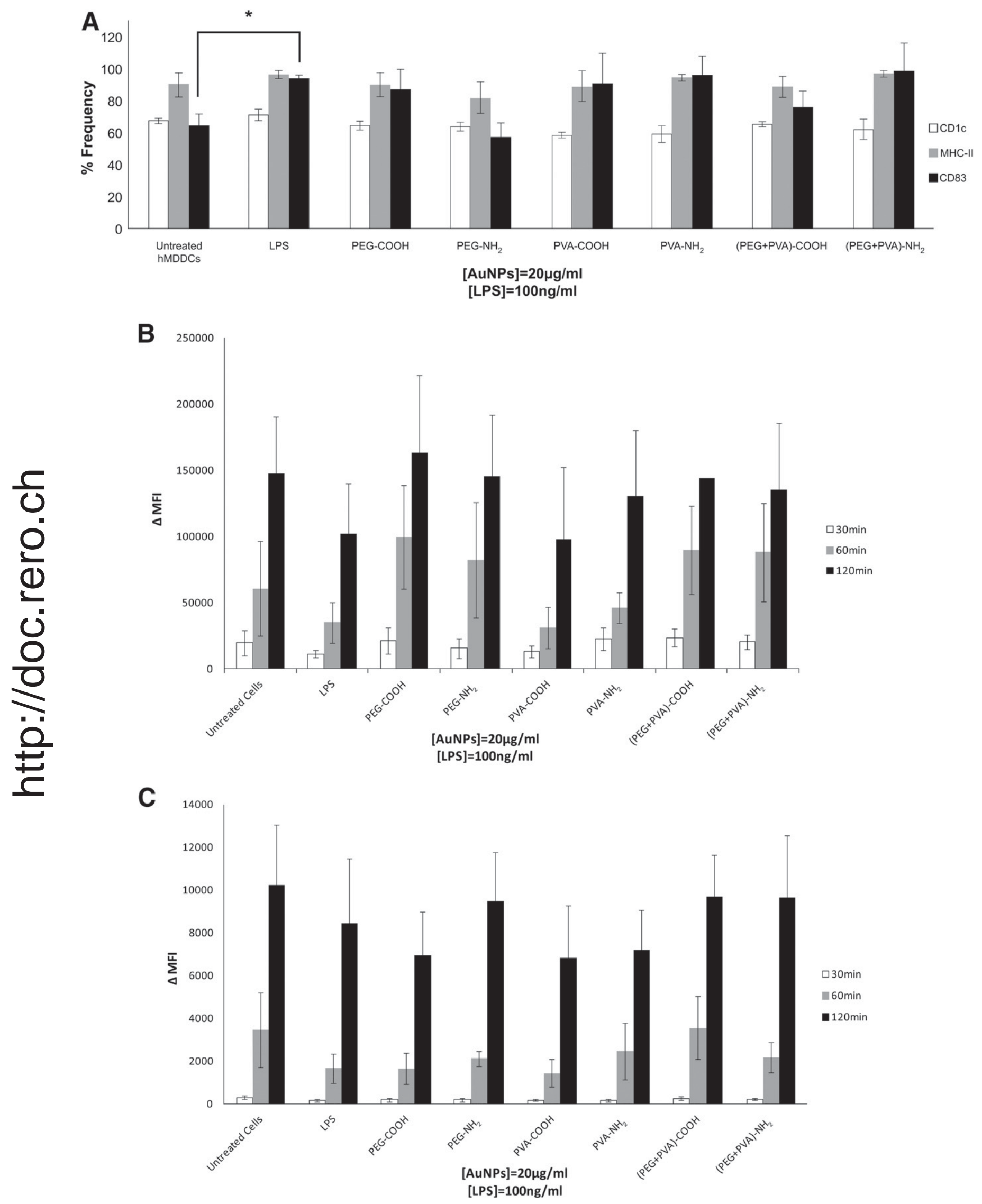
AuNPs are among the most promising agents for biomedical applications, also due to their ease of synthesis and low cytotoxicity. ${ }^{10,12,34}$ In order to evaluate how surface modification can modulate the interaction with MDDCs, a library of AuNPs was established. With a gold core and covered with two different polymers, (i.e. PEG and PVA) both of them already FDA approved. ${ }^{28,35}$ Functionalized groups were attached to the surface to induce either a positive (NH2-groups) or a negative charge (COOH-groups). Synthesized particles were characterized by various techniques such as DLS, UV-Vis, zeta-potential, and absence of agglomeration in cell culture media over $24 \mathrm{~h}$ was verified. It is absolutely essential to thoroughly characterize any new designed NP at each modification step in the engineering process to obtain reliable data, which truly reflects the particle properties independent from agglomeration in the medium. Analysis by DLS showed that carboxyl-functional PEG AuNPs display a larger hydrodynamic diameter than aminefunctional PEG AuNPs, despite a similar molecular weight $(\mathrm{Mw}=5000)$ for both PEG polymers. The difference in diameter could be attributed to different PEG surface coverages on AuNPs and was previously described by Manson et $\mathrm{al}^{36}$ who showed that the hydrodynamic diameter of AuNPs increased from $8 \mathrm{~nm}$ to $19 \mathrm{~nm}$ as function of capping density. PVA- $\mathrm{NH}_{2}$ and (PEG + PVA)-NH $\mathrm{NH}_{2}$ coated AuNPs showed the largest diameters (Table 1), which can be explained by the presence of amine-PVA with a Mw of 240,000, which is 48 fold higher than the molecular weight of PEG and 4.8-8 fold higher than the corresponding PVA-COOH. Also, electrostatic repulsion plays an important role: as the number of charges $\left(-\mathrm{NH}_{3}^{+}\right)$is higher in the amine-PVA, the electrostatic repulsion between the polymer chains also increases, ${ }^{36}$ resulting in a higher hydrodynamic diameter. However, when surface functionalized, AuNPs displayed negative zeta potentials, despite containing positively charged amine groups $\left(-\mathrm{NH}_{3}^{+}\right)$. This may be attributed to the reduced number of protonated amino groups (1.5-2 fold; $\mathrm{pKa}$ $\sim 8.5-9.5)$ at $\mathrm{pH} 7$ and the formation of hydrogen bonds between the polymer chain (i.e. $\mathrm{PEG}-\mathrm{NH}_{2}$ or $(\mathrm{PEG}+\mathrm{PVA})-\mathrm{NH}_{2}$ ) and either remaining citrate ions ${ }^{37}$ or phosphate ions. ${ }^{38}$ Endotoxin levels were found to be below 0.1 endotoxin unit $/ \mathrm{mL}(\mathrm{EU} / \mathrm{mL})$ for all AuNP types tested.

Recently these particles were labeled with a fluorophore to facilitate their detection. The polymer labeling with a fluorophore can fundamentally alter particle properties and modulate cellular uptake by MDDCs. ${ }^{39}$ To avoid the effects of a fluorophore, we employed unlabeled AuNPs in the current study and investigated how such particles may functionally modulate dendritic cells.

The cellular uptake study confirms that surface modifications can result in different levels of cell-associated AuNPs. It is important to mention that both methods used (i.e. the $\mathrm{Au}$ quantification by ICP-OES and the visual investigation of
AuNPs in MDDCs by TEM) revealed comparable results, by keeping in mind that ICP-OES cannot distinguish between particles that are associated with the cells, i.e. attached to the outer cell membrane, or inside the cells. As expected, PEG-COOH coated NPs, with their high hydrophobicity and negative surface charge, showed the lowest uptake at the lower dose in comparison to all other particles. Other studies also reported that PEG prevents cellular uptake. ${ }^{30,34,35}$ These findings are also in agreement with the literature where it has been shown that negatively charged particles present a lower cell interaction. ${ }^{40}$ However, uptake of the positively charged polymer coated AuNPs cannot be explained by the surface charge alone. The higher internalization of $\mathrm{PVA}-\mathrm{NH}_{2}$ particles compared to $\mathrm{PEG}-\mathrm{NH}_{2}$ (6-8 fold) and ( $\left.\mathrm{PEG}+\mathrm{PVA}\right)-\mathrm{NH}_{2}$ ( 2 fold) may be attributed to the PEG polymer, since many reports have shown that PEG coated NPs only weakly interact with cells resulting in long circulation times in vivo. ${ }^{34}$

Most of the AuNPs were found aggregated inside cells, as shown by TEM images. For the PVA-NH2 AuNPs, also highly agglomerated particles inside vesicles have been observed. It has been discussed by Brandenberger et al that agglomeration occurs intracellularly and can increase with time. ${ }^{34}$ For the PEG-COOH AuNPs we also have observed particles free in the cytosol. It has been shown by means of stereology that the cytosol is not a preferred cellular compartment for NPs, although the surface modulation of NPs can affect the intracellular trafficking into the cytosol. ${ }^{34}$ However, we did not find any correlation of the uptake rate with either the polymer (i.e. PVA, PEG, PEG + PVA) or the surface charge (i.e. $\mathrm{NH} 2$ or $\mathrm{COOH}$ ). Therefore it is suggested that a combination of the polymer and the specific surface charge contributes to NP uptake, although further research is necessary to evaluate this hypothesis. Another possibility might be a different protein adsorption onto the NP surface following incubation in cell culture media complemented with FCS, however, we recently showed that the protein profiles adsorbed onto iron oxide nanoparticles were similar, regardless of the polymer coating and charge. ${ }^{30}$

Exposure of cells to any AuNPs type at $20 \mu \mathrm{g} / \mathrm{mL}$ did not impair cell viability. Attenuating or increasing effects of particles in the presence of an inflammatory stimulus was also investigated. At the lowest AuNP concentration no diminishing effects were observed upon cell viability. However, a significant decrease in cell viability was observed when both untreated and LPS-treated cells were exposed to PVA-NH2 at $100 \mu \mathrm{g} / \mathrm{mL}$. It also has been shown by Wittmar and Nguyen that aminated PVA can cause cytotoxicity in L929 mouse fibroblasts and SKOV-luc human ovary cancer cells. ${ }^{41,42}$

The potential for AuNPs to cause a (pro-)inflammatory cellular response was addressed by measuring cytokine secretion. TNF- $\alpha$ and IL-1 $\beta$ have been investigated, since they are involved in lung diseases by the activation of different

Figure 5. Expression of phenotype and maturation markers as well as antigen uptake and processing in MDDC after AuNPs exposure. (A) AuNPs do not alter CD1c, CD83 and MHC-II expression. Untreated cells were used as negative and cells with $100 \mathrm{ng} / \mathrm{mL}$ LPS as positive control. Results are expressed as $\%$ frequency of positive cells (error bars: mean $\pm \mathrm{SD},{ }^{*} P<0.05, \mathrm{n}=3$ ). (B) After particle exposure, samples were incubated with OVA-Alexa647 for the testing of the antigen uptake capacity. The fluorescence intensity was examined by flow cytometry (error bars: $\mathrm{mean} \pm \mathrm{SD}, \mathrm{n}=3$ ). (C) After particle exposure, samples were incubated with DQ-OVA for the testing of the antigen uptake capacity. The fluorescence intensity was examined by flow cytometry (error bars: mean $\pm \mathrm{SD}, \mathrm{n}=3$ ). 
(pro-)inflammation pathways and the inflammasome activation pathway. ${ }^{43}$ We did not measure significant amounts of pro-inflammatory and inflammasome cytokines in most of the AuNP treated cells. Only PEG-COOH AuNPs induced a significant TNF- $\alpha$ release at all tested concentrations, whereas the highest concentration of PVA-NH2 and (PEG + PVA)-NH2 AuNPs induced release of IL-1 $\beta$. Interestingly, in the presence of LPS, a reversal of TNF- $\alpha$ secretion was noted for PVA-NH $\mathrm{N}_{2}$, PEG-NH ${ }_{2}$ and PVA-COOH AuNPs. For the PVA-NH ${ }_{2}$ this reversal can be attributed to the increased cytotoxicity observed with these AuNPs at this time point. While the PEG-NH$H_{2}$ and PVA-COOH AuNPs have been shown not to interfere with LPS (Table S2) the present data are supported by a recent article by Piazza and colleagues, ${ }^{44}$ who also showed that LPS, when loaded onto the surface of magnetic NPs can cause a decrease in TNF- $\alpha$ production from mouse bone-marrow derived dendritic cells which were exposed to $0.01-1 \mu \mathrm{g} / \mathrm{mL}$ for $24 \mathrm{~h}$, Thus, these findings highlight the ability for NPs to suppress TNF- $\alpha$ secretion in the presence of LPS. Further research is required to further determine the mechanisms of this aspect.

Similarly, the PEG- $\mathrm{NH}_{2}$, (PEG + PVA)-COOH and PVA-NH $\mathrm{N}_{2}$ and PVA-COOH also showed a reversal in IL- $1 \beta$ secretion. For the PVA-NH${ }_{2}$ AuNPs this can be associated to the increased level of cytotoxicity that they caused to the MDDCs. Yet, for the other AuNPs these findings could be attributed to recent research by $\mathrm{Wu}$ et $\mathrm{al}^{45}$ who demonstrated that IL-1 $\beta$ is down-regulated on LPS-stimulated murine microglial cells by the addition of $10 \mu \mathrm{g} / \mathrm{mL}$ iron oxide NPs, via the secretory lysosomal pathway of cytokine processing, as well as Sumbayev et $\mathrm{al}^{46}$ who reported IL- $1 \beta$ down-regulation to be associated with aggregation of IL-1 $\beta$ molecules around the surface of the NP. Interestingly, the augmentation of the IL- $1 \beta$ secretion was only found for (PEG + PVA)-NH $\mathrm{N}_{2}$ AuNPs at $100 \mu \mathrm{g} / \mathrm{mL}$. This effect can be attributed to the fact, as recently shown by Niikura et al that the (PEG + PVA)-NH $\mathrm{NH}_{2}$ AuNPs were internalized, as analyzed via ICP-OES, at high numbers and so can be subsequently associated with potential lysosomal rupture eluding to an increased IL-1 $\beta$ secretion.

Sumbayev and co-workers $(2012)^{46}$ have reported that citrate coated AuNPs have the potential to down-regulate IL-1 $\beta$ expression in human macrophages. Furthermore, $\mathrm{Wu}$ and colleagues $^{45}$ reported that iron oxide NPs down-regulated IL-1 $\beta$ expression and had no effect on TNF- $\alpha$ production in murine microglia cells. The results gained within the present study are not in agreement with these results, likely due to the use of different cell and NP types.

Niikura et $\mathrm{al}^{43}$ employed AuNPs of different sizes and shapes to immune cells and stated that TNF- $\alpha$ and IL-1 $\beta$ were not significantly secreted when RAW264.7 macrophages were exposed to $20 \mathrm{~nm}$ spherical AuNPs, while for other AuNPs with different shape (i.e. nanorods, nanocubes) significant cytokine secretion was observed. It was shown that a correlation between the size and shape of AuNPs, dependent upon their surface area, can contribute to the observed immune responses. In light of this, a correlation analysis of the AuNPs uptake with their (pro-)inflammatory effects was performed. No correlation between AuNPs uptake and cytokine secretion by MDDCs was observed $\left(\mathrm{R}^{2}\right.$ values ranging from 0.04 to 0.639 , as shown in the
SI and in Figure S8). With 5.1 pg Au per MDDC, PEG-COOH elicited a significant upregulation of TNF- $\alpha$, while the highest intracellular Au content (348.7 pg Au/cell) of PVA-NH2 AuNPs did not induce TNF- $\alpha$, but increased IL-1 $\beta$ secretion. Importantly, all AuNP types at the lower concentration tested failed to induce IL-1 $\beta$, of which increased levels can result in lysosome rupture, causing leakage of proteolytic enzymes into the cytosol. ${ }^{43}$

CD1c together with MHC-II and CD83 are important surface markers for MDDC characterization as their immunological status. ${ }^{47,48}$ The frequency of cells expressing CD1c (phenotype) and MHC-II (activation) was not altered when MDDCs, even when LPS-co-stimulated, were exposed to any of the AuNPs tested. The high frequency of MHC-II positive cells in control cultures can be explained by the stress of the monocyte isolation and differentiation process. LPS addition significantly increased, as expected, CD83 which is a maturation marker for MDDCs and involved in T-cell activation. ${ }^{47,49,50}$ Interestingly, antigen uptake and processing were not impaired when MDDC was exposed to $20 \mu \mathrm{g} / \mathrm{mL}$ AuNPs. This is contrary to another study with PVA-coated iron oxide NPs at the same concentration and using the same assays as here, where antigen processing was decreased, ${ }^{1}$ therefore these immune tests have to be performed for all new designed NPs.

We have established a library of AuNPs capable for uptake by cells of the immune system (i.e. MDDCs). The synthesis, characterization and various surface functionalizations of AuNPs can be controlled at any process stage and give reproducible results. Specific surface modification to AuNPs can tune their cellular uptake with the lowest internalized concentration observed for PEG-COOH AuNPs, while the highest was for the PEG + PVA-NH2 and PVA-NH2 AuNPs. Although the PEG-COOH AuNPs triggered a limited cell uptake compared to other AuNP types a significant TNF- $\alpha$ release was observed that was not seen with any other AuNP type. Due to these differences, the cellular uptake of various AuNPs was not correlated with cytokine secretion. Finally it has been shown that the AuNPs do not interfere with any of the investigated immune functions in the cells such as phenotype (CD1c) and maturation change (MHC-II and $\mathrm{CD} 83$ ), antigen uptake and processing.

In order to design innovative nanocarriers as pulmonary vaccination systems the carrier itself requires a thorough investigation about the interaction with immune cells. Our results clearly indicate that surface properties of AuNPs, such as the chemical composition and surface charge modulate uptake by MDDCs and cytokines release. However, uptake as well as cytokine release could not be correlated to the surface chemistry and/or surface charge of NPs. PEG-COOH AuNPs increased TNF $\alpha$-release, whereas the highest concentrations of PVA- $\mathrm{NH}_{2}$ and ( $\left.\mathrm{PEG}+\mathrm{PVA}\right)-\mathrm{NH}_{2}$ AuNPs induced IL-1 $\beta$ production. Since the AuNPs employed in this study triggered MDDC responses in vitro, their development as novel vaccine carriers for vaccines requires further investigations in vivo to delineate downstream immune responses.

\section{Appendix A. Supplementary data}

Supplementary data to this article can be found online at http://dx.doi.org/10.1016/j.nano.2014.11.004. 


\section{References}

1. Blank F, Gerber P, Rothen-Rutishauser B, Sakulkhu U, Salaklang J, de Peyer K, et al. Biomedical nanoparticles modulate specific CD4+ T cell stimulation by inhibition of antigen processing in dendritic cells. $\mathrm{Na}$ notoxicology 2011;1(16).

2. Blank F, Stumbles PA, Seydoux E, Holt PG, Fink A, RothenRutishauser B, et al. Size-dependent uptake of particles by pulmonary APC populations and trafficking to regional lymph nodes. Am J Respir Cell Mol Biol 2013;49(1):67-77.

3. Hirosuea S, Kourtis IC, van der Vlies AJ, Hubbell JA, Swartz MA. Antigen delivery to dendritic cells by poly(propylene sulfide) nanoparticles with disulfide conjugated peptides: cross-presentation and $\mathrm{T}$ cell activation. Vaccine 2010;28:7897-906.

4. Hubbell JA, Thomas SN, Swartz MA. Materials engineering for immunomodulation. Nature 2009;462(26).

5. Swartz M, Hirosue S, Hubbell JA. Engineering approaches to immunotherapy. Sci Transl Med 2012;4(148).

6. Moghimi SM, Hunter AC, Murray JC. Nanomedicine: current status and future prospects. FASEB J 2005;19:311-30.

7. Card JW, Zeldin DC, Bonner JC, Nestmann ER. Pulmonary applications and toxicity of engineered nanoparticles. Am J Physiol Lung Cell Mol Physiol 2008;295.

8. Ghosh P, Han G, De M, Kim CK, Rotello VM. Gold nanoparticles in delivery applications. Adv Drug Deliv Rev 2008;60.

9. Murphy C, Gole AM, Stone JW, Sisco PN, Alkilany AM, Goldsmith EC, et al. Gold nanoparticles in biology: beyond toxicity to cellular imaging. Acc Chem Res 2008;41(12):1721-30.

10. Kimling J, Maier M, Okenve B, Kotaidis V, Ballot H, Plech A. Turkevich method for gold nanoparticle synthesis revisited. $J$ Phys Chem B 2006;110:15700-7.

11. Fadeel B. Clear and present danger? Engineered nanoparticles and the immune system. Swiss Medial Wkly 2012;142(w13609):1-9.

12. Thakor AS, Jokerst J, Zavaleta C, Massoud TF, Gambhir SS. Gold nanoparticles: a revival in precious metal administration to patients. Nano Lett 2011:4029-36.

13. Müller L, Gasser M, Raemy DO, Herzog F, Brandenberger C, Schmid O, et al. Realistic exposure methods for investigating the interaction of nanoparticles with the lung at the air-liquid interface in vitro. InSci $J$ 2011;1(1):30-64.

14. Gehr P, Bachofen M, Weibel ER. The normal human lung: ultrastructure and morphometric estimation of diffusion capacity. Respir Physiol 1978;32:121-40.

15. von Garnier C, Nicod LP. Immunology taught by lung dendritic cells. Swiss Medial Wkly 2009;139(13-14):186-92.

16. Holt PG, Strickland DH, Wikström ME, Jahnsen FL. Regulation of immunological homeostasis in the respiratory tract. Nat Rev Immunol 2008;8.

17. Demedts IK, Brusselle GG, Vermaelen KY, Pauwels RA. Identification and characterization of human pulmonary dendritic cells. Am J Respir Cell Mol Biol 2005;32:177-84.

18. Mellman I, Steinman RM. Dendritic cells: specialized and regulated antigen processing machines. Cell 2001;106:255-8.

19. Vermaelen K, Pauwels R. Pulmonary dendritic cells. Am J Respir Crit Care Med 2005;172.

20. Randall TD. Pulmonary dendritic cells: thinking globally, acting locally. $J$ Exp Med 2010;207(3).

21. Holt PG, Stumbles PA. Characterization of dendritic cell populations in the respiratory tract. J Aerosol Med 2000;13:361-7.

22. Shukla R, Bansal V, Chaudhary M, Basu A, Bhonde RR, Sastry M. Biocompatibility of gold nanoparticles and their endocytotic fate inside the cellular compartment: a microscopic overview. Langmuir 2005;21:10654-20644.

23. Villiers CL, Freitas H, Couderc R, Villiers MB, Marche PN. Analysis of the toxicity of gold nano particles on the immune system: effect on dendritic cell functions. J Nanopart Res 2010;12:55-60.
24. Thomas SN, van der Vlies AJ, O’Neil CP, Reddy ST, Yu SS, Giorgio DT, et al. Engineering complement activation on polypropylene sulfide vaccine nanoparticles. Biomaterials 2011;32:2194-203.

25. Sung JC, Pulliam BL, Edwards DA. Nanoparticles for drug delivery to the lungs. Trends Biotechnol 2007;25(12):563-70.

26. Turkevich J, Stevenson PC, Hillier J. A study of the nucleation and growth processes in the synthesis of colloidal gold. Discuss Faraday Soc 1951;11:55-75.

27. Frens G. Controlled nucleation for the regulation of the particle size in monodisperse gold suspensions. Nat Phys Sci 1973;241:20-2.

28. EFSA. Opinion of the Scientific Panel on Food Additives, Flavourings, Processing Aids and Materials in Contact with Food on a request from the Commission related to the use of polyvinyl alcohol as a coating agent for food supplements (Question number EFSA-Q-2005-017), in The EFSA Journal; 20051-15.

29. Alconel SNS, Baas AS, Maynard HD. FDA-approved poly(ethylene glycol)-protein conjugate drugs. Polym Chem 2011;2(1442).

30. Hirsch V, Kinnear C, Moniatte M, Rothen-Rutishauser B, Clift MJD, Fink A. Surface charge of polymer coated SPIONs influences the serum protein adsorption, colloidal stability and subsequent cell interaction in vitro 7. Nanoscale 2013;5(9):3723-32.

31. Mock JJ, Smith DR, Schultz S. Local refractive index dependence of plasmon resonance spectra from individual nanoparticles. Nano Lett 2003;3:485-91.

32. Aili D, Gryko P, Sepulveda B, Dich JAG, K. N, Heenan R, et al. Polypeptide Folding-mediated tuning of the optical and structural properties of gold nanoparticle assemblies. Nano Lett 2011;11:5564-73.

33. Dobrynin AV, Rubinsteirn M. Theory of polyelectrolytes in solutions and at surfaces. Prog Polym Sci 2005;30:1049-118.

34. Brandenberger C, Muhlfeld C, Ali Z, Lenz AG, Schmid O, Parak WJ, et al. Quantitative evaluation of cellular uptake and trafficking of plain and polyethylene glycol-coated gold nanoparticles. Small 2 2010;6(15):1669-78.

35. Karakoti AS, Soumen DS, Thevuthasan S, Seal S. PEGylated inorganic nanoparticles. Angew Chem Int Ed 2011;50:1980-94.

36. Manson J, Kumar D, Meenan BJ, Dixon D. Polyethylene glycol functionalized gold nanoparticles: the influence of capping density on stability in various media. Gold Bull 2011;44(2):99-105.

37. Wang FK, Phonthammachai N, Mya KY, Tjiu WW, He CB. PEG-POSS assisted facile preparation of amphiphilic gold nanoparticles and interface formation of Janus nanoparticles. Chem Commun 2011;47(2):767-9.

38. Sigroni F, Solario R, Lips PAM. Segmented multifunctional poly(ether ester) polymers containing H-bonding units. Preparation and characterization. Macromol Chem Phys 2004;205:1299-308.

39. Rodriguez-Lorenzo L, Fytianos K, Blank F, von Garnier C, RothenRutishauser B, Petri-Fink A. Fluorescence-encoded gold nanoparticles: library design and modulation of cellular uptake into dendritic cells. Small 2014;10(7):1341-50.

40. Huhn D, Kantner K, Geidel C, Brandholt S, De Cock I, Soenen SJH, et al. Polymer-coated nanoparticles interacting with proteins and cells: focusing on the sign of the net charge. ACS Nano 2013;7(4):3253-63.

41. Wittmar M, Ellis JS, Morell F, Unger F, Schumacher JC, Roberts CJ, et al. Biophysical and transfection studies of an amine-modified poly(vinyl alcohol) for gene delivery. Bioconjug Chem 2005;16:1390-8.

42. Nguyen J, Reul R, Roesler S, Dayyoub E, Schmehl T, Gessler T, et al. Amine-modified poly(vinyl alcohol)s as non-viral vectors for siRNA delivery: effects of the degree of amine substitution on physicochemical properties and knockdown efficiency. Pharm Res 2010;27:2670-82.

43. Niikura K, Matsunaga T, Suzuki T, Kobayashi S, Yamaguchi H, Orba Y, et al. Gold nanoparticles as a vaccine platform: influence of size and shape on immunological responses in vitro and in vivo. ACS Nano 2013;7(5):3926-38.

44. Piazza M, Collombo M, Zanoni I, Granucci F, Tortora P, Weiss J, et al. Uniform LPS loaded magnetic nanoparticles for the investigation of LPS/TLR4 signalling. Angew Chem Int Ed Engl 2011;50(3):622-6. 
45. Wu HY, Chung MC, Wang CC, Huang CH, Liang HJ, Jan TR. Iron oxide nanoparticles suppress the production of IL-1beta via the secretory lysosomal pathway in murine microglial cells. Part Fibre Toxicol 2013;10(46).

46. Sumbayev VV, Yasinska IM, Garcia CP, Gilliland D, Lall GS, Gibbs $\mathrm{BF}$, et al. Gold nanoparticles downregulate interleukin-1- $\beta$-induced proinflammatory responses. Small Nano Micro 2012:1-6.

47. Lechmann M, Berchtold S, Hauber J, Steinkasserer A. CD83 on dendritic cells: more than just a marker for maturation. Trends Immunol 2002;23(6).
48. Banchereau J, Briere F, Caux C, Davoust J, Lebecque S, Liu YJ, et al. Immunobiology of dendritic cells. Annu Rev Immunol 2000;18: 767-811.

49. Fujimoto Y, Tedder TF. CD83: a regulatory molecule of the immune system with great potential for therapeutic application. J Med Dent Sci 2006;53:85-91.

50. Prechtel AT, Steinkasserer A. CD83: an update on functions and prospects of the maturation marker of dendritic cells. Arch Dermatol Res 2007;299(2):59-69. 